\title{
Soil moisture controlled the variability of air temperature and oasis effect in a large inland basin in arid region
}

\author{
Xingming $\mathrm{Hao}^{1}$, Haochao Hao ${ }^{1}$, and Jingjing Zhang ${ }^{1}$ \\ ${ }^{1}$ Xinjiang Institute of Ecology and Geography, Chinese Academy of Sciences
}

November 11, 2020

\begin{abstract}
Soil moisture plays a significant role in land-atmosphere interactions. Changing fractions of latent and sensible heat fluxes caused by soil moisture variations can affect near-surface air temperature, thus influencing the cooling effect of the oasis in arid regions. In this study, the framework for the evaporative fraction (EF) dependence on soil moisture is used to analyze the impacts of soil moisture variation on near-surface air temperature and the oasis effect. The results showed that the contribution rate of soil moisture to $\mathrm{EF}$ was significantly higher than that of $\mathrm{EF}$ to temperature. Under the interaction of temperature sensitivity to EF and EF to soil moisture, the [?]T/[?] presented a similar tempo-spatial variation with both of the above. It was most significant in oasis areas during summer (-1.676), while it was weaker in plain desert areas during the autumn (-0.071). In the study region, the effect of soil moisture variation on air temperature can reach $0.018-0.242 \mathrm{~K}$ for different land-cover types in summer. The maximum variation of soil moisture in summer can alter air temperature by up to $0.386 \mathrm{~K}$. The difference in temperature variability between the oasis and desert areas promoted the formation of the oasis effect. For different oasis, the multi-year average oasis cold effect index (OCI) ranged from $-1.36 \mathrm{~K}$ to $-0.26 \mathrm{~K}$, while average summer OCI ranged from -1.38 $\mathrm{K}$ to $-0.29 \mathrm{~K}$. The lower bound of the cooling effect of oasis ranged from -4.97 to $-1.69 \mathrm{~K}$. The analysis framework and results of this study will provide a new perspective for further research on the evolution process of the oasis effect and water-heat balance in arid areas.
\end{abstract}

\section{Hosted file}

Mancscript9.28.pdf available at https://authorea.com/users/374897/articles/492289-soilmoisture-controlled-the-variability-of-air-temperature-and-oasis-effect-in-a-largeinland-basin-in-arid-region 


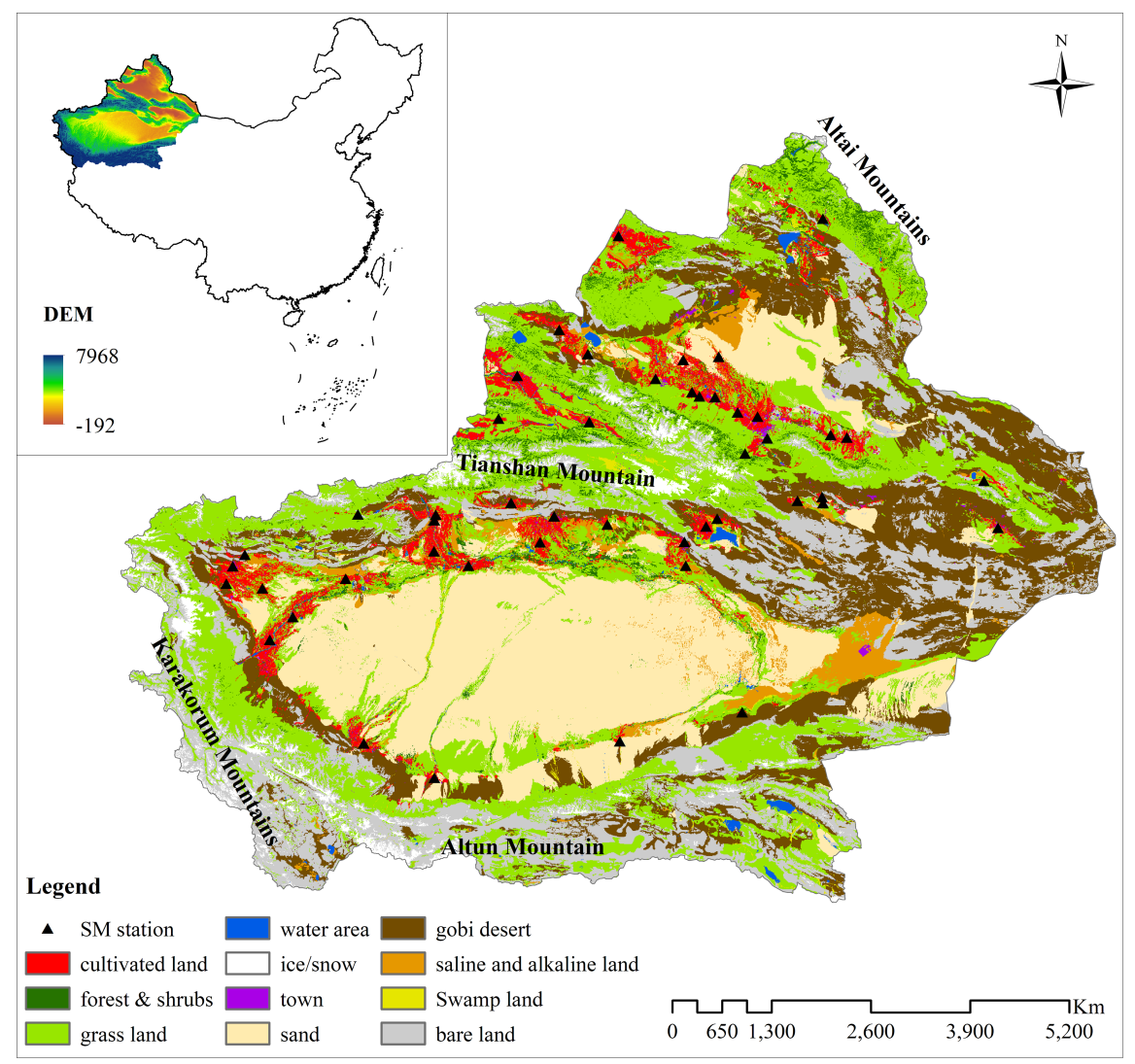




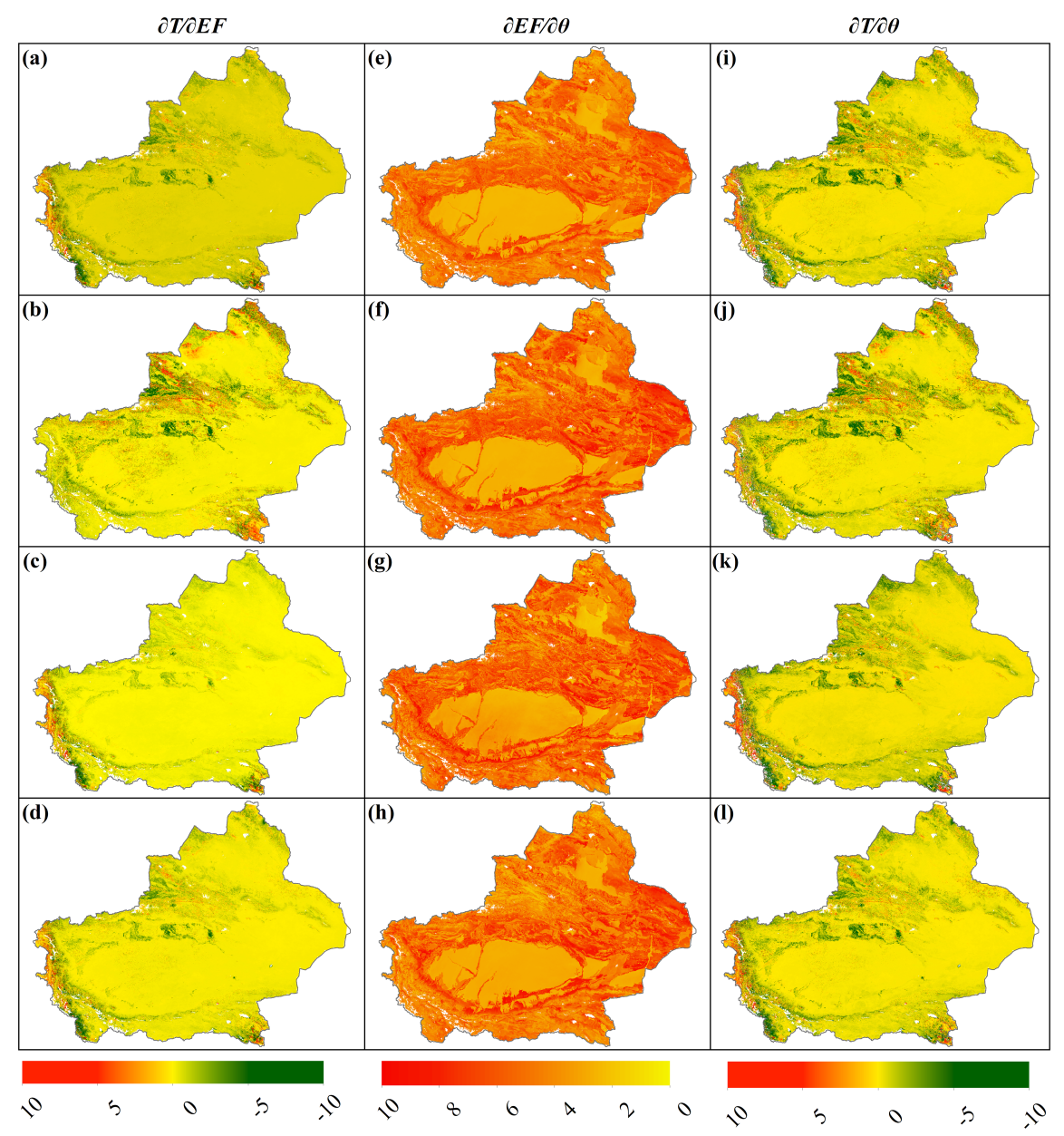



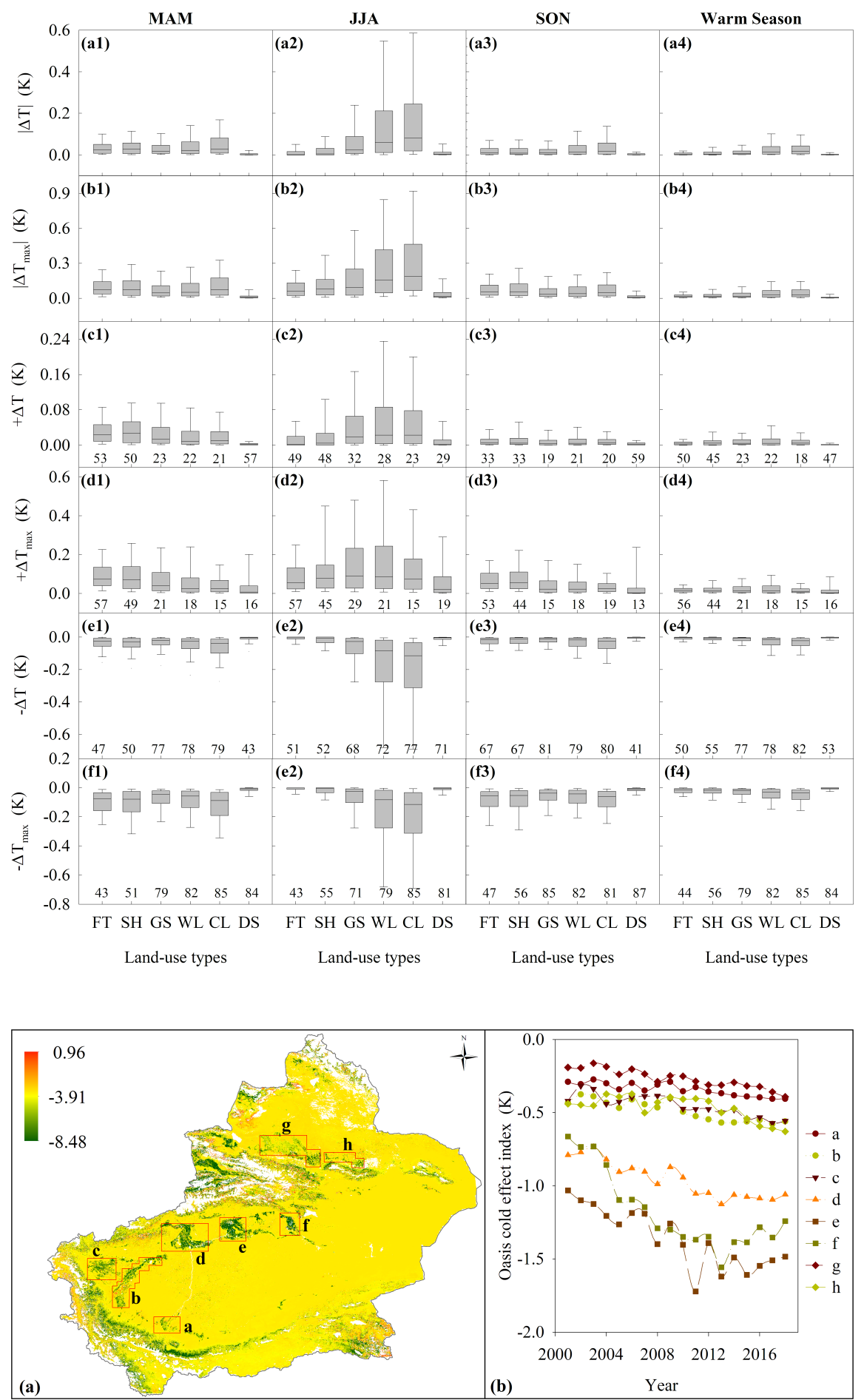

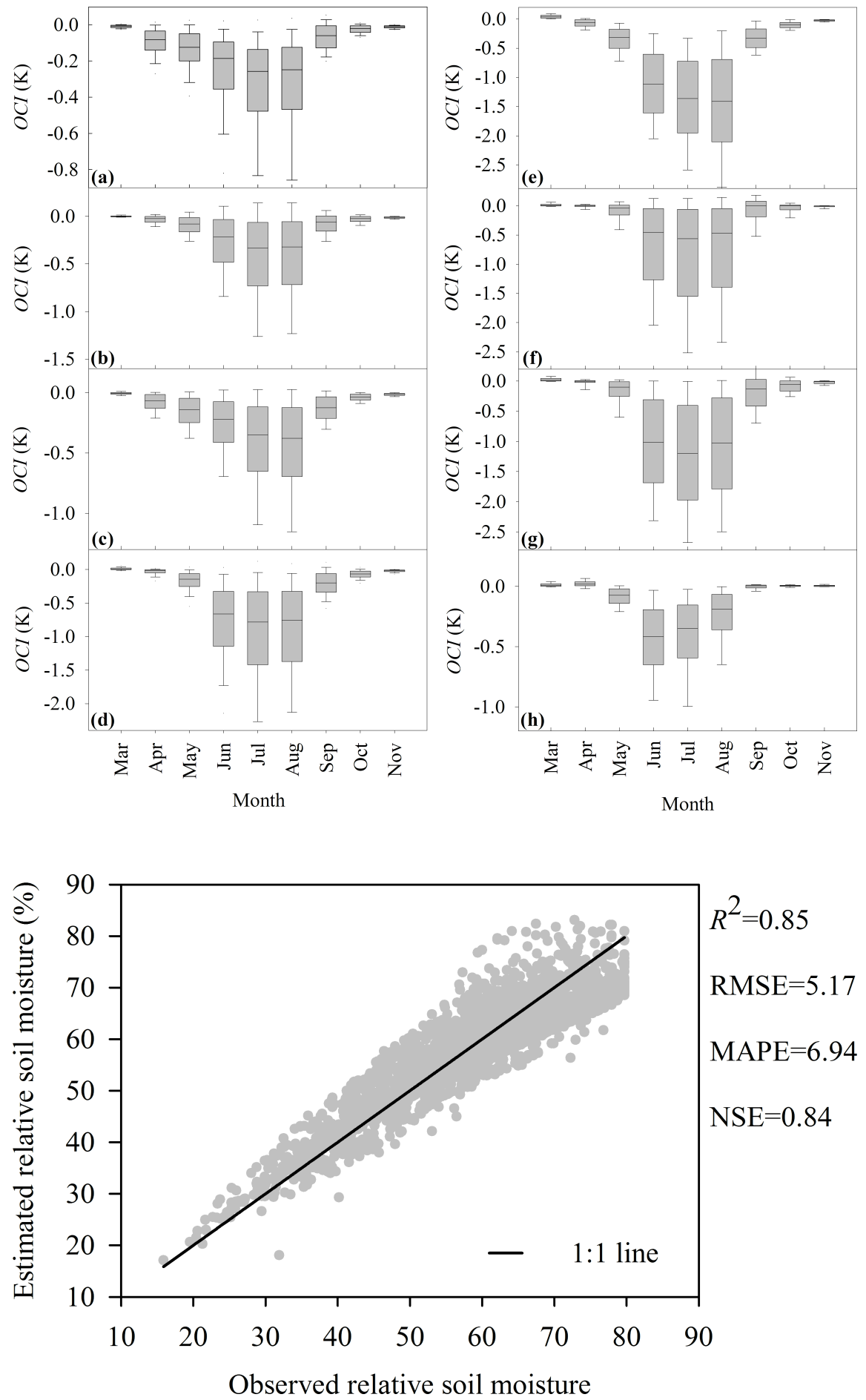